\title{
INOVAR PARA FAZER ACONTECER: COMO ESTAMOS FORTALECENDO REDES DE APOIO À EDUCAÇÃO INCLUSIVA
}

\author{
INOVAR PARA HACER QUE OCURRA: CÓMO ESTAMOS \\ FORTALECIENDO REDES DE APOYO A LA EDUCACIÓN INCLUSIVA
}

\author{
INNOVATE TO MAKE IT HAPPEN: HOW WE ARE STRENGTHENING \\ SUPPORT NETWORKS FOR INCLUSIVE EDUCATION
}

\author{
Maria Teresa Eglér MANTOAN ${ }^{1}$ \\ Maria Isabel Sampaio Dias BAPTISTA ${ }^{2}$
}

RESUMO: Diante dos desafios da implementação da Política Nacional de Educação Especial na Perspectiva da Educação Inclusiva (PNEEPEI/MEC, 2018) propusemos e estamos desenvolvendo nestes 10 anos propostas inovadoras de formação de professores do ensino regular e especial. O caráter aberto e autônomo das iniciativas a serem apresentadas neste artigo traz inovações que condizem com o intuito da PNEEPEI no que diz respeito à autonomia do aprendiz/professor. Tais iniciativas têm demonstrado resultados animadores e consistentes, quando se trata de atingir um grande número de profissionais e interessados no assunto e podem ser uma alternativa para atender às necessidades de levar os conceitos e práticas que sustentam o ensino inclusivo aos mais distantes pontos deste país.

PALAVRAS-CHAVE: Formação de professores. Inclusão escolar. Ensino autônomo.

RESUMEN: Ante los desafíos de la implementación de la Política Nacional de Educación Especial, Perspectiva de la Educación Inclusiva (PNEEPEI / MEC, 2018) propusimos y estamos desarrollando en estos 10 años propuestas innovadoras de formación de profesores del enseñanza regular y especial. El carácter abierto y autónomo de las iniciativas a ser que se presentan en este artículo trae innovaciones que concuerdan con el propósito de la PNEEPEI en el que se refiere a la autonomía del aprendiz / profesor. Tales iniciativas han demostrado resultados alentadores y consistentes, cuando se trata de alcanzar un gran número de profesionales y interesados en el tema y pueden ser una alternativa para atender a las necesidades de llevar los conceptos, prácticas que sustentan la enseñanza inclusiva a los más distantes puntos de este país.

\footnotetext{
${ }^{1}$ Universidade Estadual de Campinas (UNICAMP), Campinas - SP - Brasil. Professora do Programa de Pós-Graduação em Educação. Pedagoga, mestre e doutora em Educação. Coordenadora do Laboratório de Estudos e Pesquisas em Ensino e Diferença (LEPED). ORCID <https://orcid.org/0000-0002-4607-9880>. E-mail: tmantoan@gmail.com

2. Universidade Estadual de Campinas (UNICAMP), Campinas - SP - Brasil. Pedagoga, mestre e doutora em Educação. Vínculo com o Laboratório de Estudos e Pesquisas em Ensino e Diferenças - LEPED e com o grupo Todos Nós em Rede (TNR). ORCID <https://orcid.org/0000-0003-1747-1557>. E-mail: bel@beldias.com.br
} 
PALABRAS CLAVE: Formación de professores. Inclusión escolar. Enseñanza autónoma.

ABSTRACT: Facing the challenges of implementing the National Policy on Special Education, in the perspective of Inclusive Education (PNEEPEI / MEC, 2018) we have put forward and are developing in these 10 years innovative proposals for the training of teachers of regular and special education. The autonomous nature of initiatives to be presented in this article brings innovations aligned with the PNEEPEI's intention regarding the autonomy of the learner/teacher. Such initiatives have shown encouraging and consistent results when comes to reaching a large number of professionals interested in this subject and can be an alternative to meet the needs of bringing the concepts, practices that support inclusive education to the most distant points in our country.

KEYWORDS: Continuing Teacher Education. School Inclusion. Teacher Autonomy.

\section{Introdução}

Nestes 10 anos de implementação da Política Nacional de Educação Especial, na Perspectiva da Educação Inclusiva (PNEEPEI/MEC, 2008), o Laboratório de Estudos e Pesquisas em Ensino e Diferença (LEPED/UNICAMP), como grupo de pesquisadores interessados em inovações na prática educacional, tem reagido às provocações inerentes às novidades que essa Política traz, propondo iniciativas que atualizam a formação de professores, para atender às exigências de um ensino para todos.

Formar pessoas para o ensino inclusivo foi uma oportunidade de criarmos e de colocarmos em prática novas maneiras de ensinar sem discriminações, nunca antes propiciadas por uma política pública escolar. Embora já requerido em nosso Ordenamento Jurídico, que assegura o direito de todos os alunos, indistintamente, a estudarem com os pares de sua geração, a PNEEPEI nos convocou a repensar a escola, seus alunos e professores a partir de novos referenciais e objetivos educacionais. Resolvemos, então, com a convicção de que nosso grupo de pesquisa estava suficientemente bem ancorado teórico - metodologicamente enfrentar tal desafio. A oportunidade batia à nossa porta.

Pela participação em inúmeras iniciativas do Ministério da Educação para implementar a PNEEPEI, conseguimos medir o tamanho das dificuldades, impedimentos que teríamos de enfrentar para chegar lá, nas salas de aula, onde a educação realmente acontece, e descobrir onde atingir o ponto de mutação esperado nas formações. 
No intuito de apoiar a então Secretaria de Educação Especial (SEESP/MEC), no "Programa Educação Inclusiva: Direito à Diversidade", o LEPED e seus membros tiveram uma importante atuação nos programas de formação criados pela SEESP/MEC. Atravessamos o país de ponta a ponta, visitando os denominados Municípios polos e suas Abrangências, que estavam implantando novas práticas pedagógicas de ensino comum e especial nas suas escolas, segundo as orientações da PNEEPEI.

Ainda nesse sentido, participamos da coordenação de dois cursos de formação de professores na modalidade a distância, oferecidos em parceria com a Universidade Federal do Ceará (UFC). Formamos entre 2008/2012 mais de 6.000 professores em cursos de aperfeiçoamento e de especialização lato sensu e com essa rede de apoio foi possível acontecer o AEE nas escolas. Essas iniciativas pioneiras fizeram a sua parte, garantindo a introdução da PNEEPEI nas escolas e representaram para o LEPED mais uma bandeira de luta em favor de uma escola brasileira mais democrática, justa e para todos.

Em 2011, quando a SEESP/MEC se transformou na Secretaria de Educação Continuada, Alfabetização, Direitos Humanos, Diversidade e Inclusão (SECADI/MEC), o Programa "Educação Inclusiva: Direito à Diversidade", já existente, foi descaracterizado e ampliado com outros tópicos, deixando de ter sua atuação voltada exclusivamente para a formação de professores para a inclusão escolar de alunos da educação especial. Essa ampliação do leque de formação do Programa para atender aos novos focos de atuação da SECADI, prejudicou a continuidade dos trabalhos da rede de apoio aos professores para efetivação da inclusão escolar. Embora incipiente, ela já caminhava para uma consolidação de seus propósitos.

A supressão do "Programa Educação Inclusiva: Direito à Diversidade" formou um vácuo, que vem sendo até então, preenchido por concepções e práticas distorcidas, longe do que se propõe para que um ensino seja, de fato, inclusivo. Isso deu margem a movimentos em favor da volta às escolas e classes especiais e outros retrocessos gravíssimos para o ensino de todos os alunos. A necessidade de se continuar propiciando aos professores de educação comum e especial uma retaguarda para seus trabalhos nas escolas se prolonga até nossos dias.

Sem financiamento do MEC e de órgãos públicos estaduais e municipais poucas iniciativas relacionadas à efetivação da inclusão nas escolas estão acontecendo. Algumas redes mais envolvidas com a inclusão ainda promovem seminários, encontros 
com especialistas, para subsidiar seus professores, de modo que suas dúvidas sejam dirimidas, seus projetos e práticas realimentados.

Diante do encerramento das atividades do "Programa Educação Inclusiva: Direito à Diversidade", em 2010 e dos cursos de formação realizados em parceria com a UFC/MEC e a Universidade Aberta do Brasil, o LEPED, preocupado com a situação, reuniu-se com outros pesquisadores do Instituto de Computação (IC/ UNICAMP), uma referência na produção de inovações envolvendo a Informática no campo educacional, e com o qual já tínhamos e temos projetos em comum há um bom tempo.

Foi com esses colegas de estudos que nos unimos para repensar a formação de professores para o Atendimento Educacional Especializado (AEE), promovida anteriormente pelo MEC/UFC e demais universidades particulares que se aproveitaram da ocasião para montar inúmeros outros cursos, cada vez mais distantes do que a PNEEPEI orientava como atribuições dos professores do ensino especial e comum para a inclusão.

Queríamos mudar o modo pelo qual os professores eram formados. Nosso encontro com os pesquisadores do IC/UNICAMP foi providencial e dele surgiu a ideia de uma rede social de formação autônoma de professores, que descreveremos mais adiante. Para tanto, foi criado um sistema computacional dedicado a professores de educação inclusiva que é único como iniciativa no gênero e que os liga aos colegas de todos os cantos do país, do exterior, para trocar ideias, resolver questões, difundir conhecimentos. Esse sistema computacional se denomina Todos Nós em Rede (TNR) tnr.nied.unicamp.br.

O TNR, que conheceremos neste artigo, tem hoje mais de mil seguidores, está ativo e evoluindo, de acordo com as peculiaridades de seus membros, seus ritmos e formas de atuar e foi motivo de estudos acadêmicos de Mestrado e de Doutorado, desenvolvidos na Faculdade de Educação e no Instituto de Computação da Unicamp, dentre os quais os realizados por autores deste artigo. As dissertações e teses desenvolvidas visaram à ampliação de nossos conhecimentos sobre a evolução da rede para que pudéssemos atualizar esse sistema e melhor atender a todos os seus membros e seguidores. Dentre as pesquisas realizadas, destacamos: "Danças no TNR: movimentos de professores em formação continuada" (BAPTISTA, 2018); "O discurso de todos nós: um estudo sobre a rede social de formação continuada de professores Todos Nós em Rede". (NASCIMENTO, 2017); "Rede de Autoridades e Apoio às Interações Sociais na Web: uma Abordagem Culturalmente Informada" (PEREIRA, 2012) e "A importância 
de uma rede social para o aperfeiçoamento continuado dos profissionais do Atendimento Educacional Especializado". (CAVALCANTE, 2010).

Sempre movidos pelo interesse de conhecer os resultados trazidos pela formação oferecida aos professores de Educação Especial, o LEPED e o Instituto Pesquisas do Discurso do Sujeito Coletivo (IPDSC/SP) consultaram a opinião de pais e professores, gestores envolvidos com a inclusão em escolas urbanas e rurais de todo o país. Colhemos 3570 depoimentos em 74 escolas. O estudo aconteceu nos anos de 2013/2014 e denominou-se "A escola e suas transformações a partir da educação especial na perspectiva inclusiva" (MANTOAN, 2014). Nas conclusões desse estudo os professores do ensino comum e especial demandavam mais formação para o ensino inclusivo.

Dados como os colhidos nessa pesquisa reafirmaram nosso comprometimento com a formação de redes de apoio à efetivação da escola brasileira para todos. A contribuição do LEPED, atualmente, tem ocorrido a partir de projetos que não contam com patrocinadores ou financiamentos. Nossos pesquisadores são guiados pelo interesse, necessidades dos professores que podem usufruir dos benefícios de redes de formação nas quais participam sem custos e que possibilitam a interação entre colegas de todos os cantos do país.

Recentemente, propusemos à Escola de Extensão (EXTECAMP/UNICAMP) a realização de um conjunto de "Cursos de Difusão Cultural", cuja proposta apresentaremos adiante, neste artigo. Tais iniciativas, que estamos dando a conhecer existem, acontecem e estão sendo muito bem avaliadas por professores brasileiros, que desejam conhecer como se ensina, na perspectiva inclusiva. Elas serão expostas em maiores detalhes nos tópicos que seguem.

\section{Inovar para fazer acontecer}

\section{Todos nós em rede (TNR): uma rede autônoma de formação de professores}

A ideia de criar o sistema Todos Nós em Rede (TNR) nasceu a partir da experiência da Prof. ${ }^{a}$ Dr. ${ }^{a}$ Maria Teresa E. Mantoan e da Prof. ${ }^{a}$ Dr. ${ }^{a}$ Rita Vieira de Figueiredo na coordenação de dois cursos de formação de professores para o AEE, na modalidade a distância, promovidos em parceria com a Universidade Federal do Ceará (UFC) e no âmbito da Universidade Aberta do Brasil (UAB). Esses cursos foram financiados pelo Ministério da Educação (MEC) e a então Secretaria de Educação Especial (SEESP/MEC). O primeiro foi um curso de aperfeiçoamento oferecido em 
2009 e o segundo, um curso de especialização lato sensu em 2010/2011. Na época tais cursos envolveram mais de seis mil professores de todo país.

A experiência crítica nestes cursos de formação originou o Projeto "Redes Sociais e Autonomia Profissional: novos rumos para formação continuada a distância de professores de AEE" (PROESP/CAPES, 2009), elaborado e coordenado pela Prof.a Dr. ${ }^{a}$ Maria Cecília C. Baranauskas (Instituto de Computação/UNICAMP) e Prof. ${ }^{a}$ Dr. ${ }^{a}$ Maria Teresa E. Mantoan (Faculdade de Educação/UNICAMP).

Esse projeto teve como objetivo a constituição de uma rede social de profissionais de Atendimento Educacional Especializado (AEE), tendo em vista a formação continuada e colaborativa desses profissionais. Partimos da seguinte questão: seria possível fazer uma educação continuada mais flexível que os cursos de especialização e formação continuada a distância e ancorada nos problemas do cotidiano das professoras? Com o trabalho colaborativo entre computação e educação pudemos propor a construção de um espaço inédito no país que preconiza o aprendizado de forma contínua para professores; tem capilaridade, ou seja, chega no Brasil todo (pois é uma rede); não tem o formalismo de um curso de Educação a Distância (EaD); não tem uma estrutura hierárquica; e foi construído conjuntamente com as professoras em uma forma de trabalho colaborativo denominado design participativo (BARANAUSKAS; ROCHA, 2003).

Todos os participantes eram pessoas reais, coerentes, contraditórias, enfim; professores que atenderam a um convite para a atuação e o compartilhamento de problemas educacionais e suas possíveis soluções. O sistema Todos Nós em Rede (TNR) ofereceu condições para que os professores trocassem ideias, tomassem decisões, resolvessem seus problemas de forma cooperativa e autônoma, uma vez que propôs o desenho participativo desde o início de suas atividades. Tal concepção participativa constituiu o grande diferencial dessa rede de profissionais envolvidos com o AEE, conforme podemos observar nas Figuras n. 1, 2 e 3 a seguir:

Figura 1 - Professores participam de atividade coletiva de criação/design do sistema TNR 


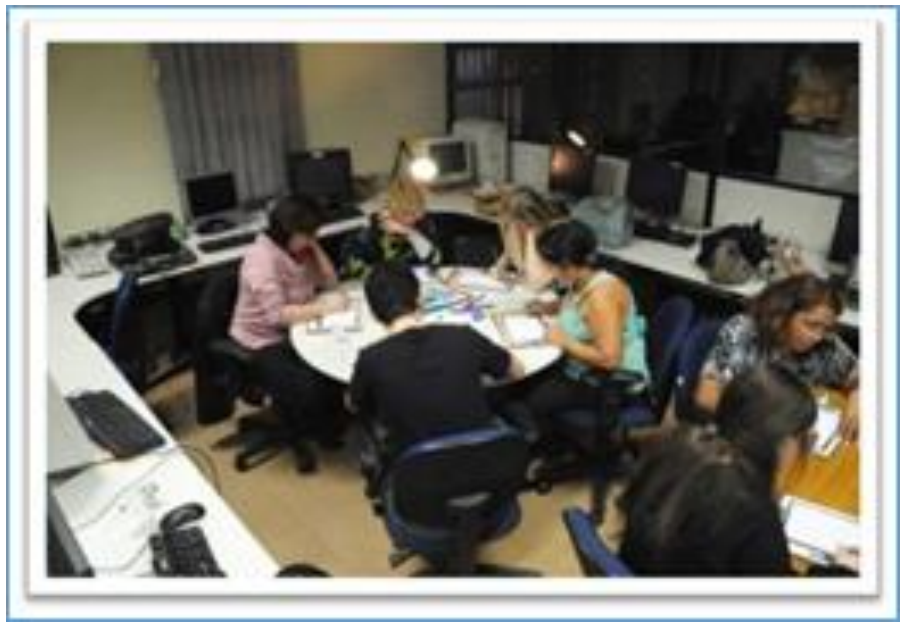

Fonte: Relatório Final PROESP/CAPES (2014)

Figura 2 - Design participativo dos professores na criação do sistema TNR.
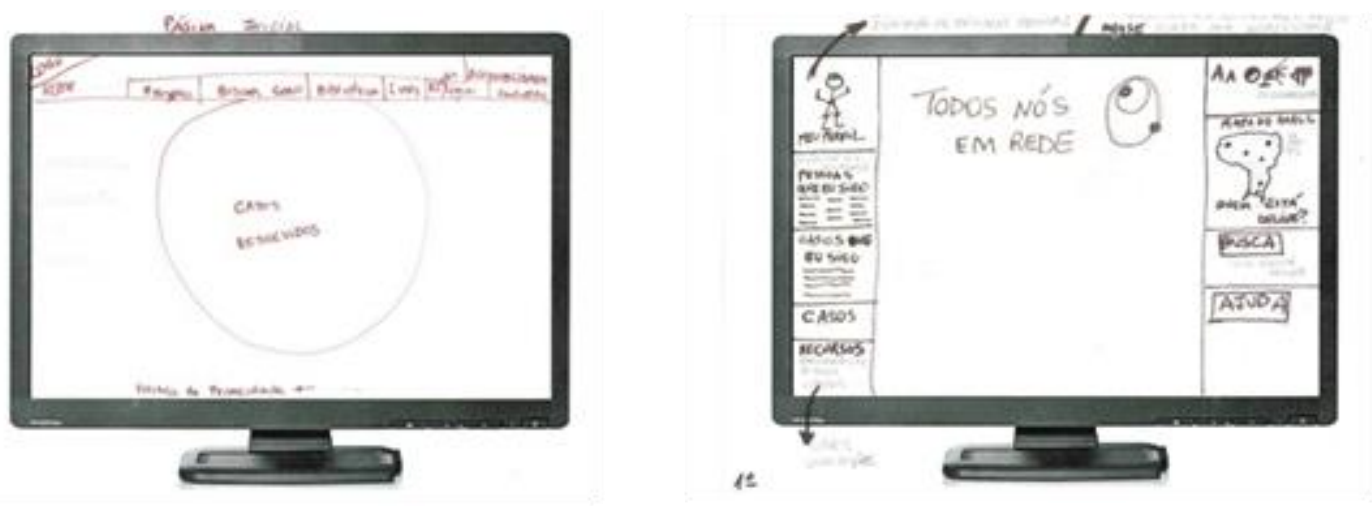

Fonte: Relatório Final PROESP/CAPES (2014)

Figura 3 - A primeira versão da página inicial do TNR (publicada em 2011)

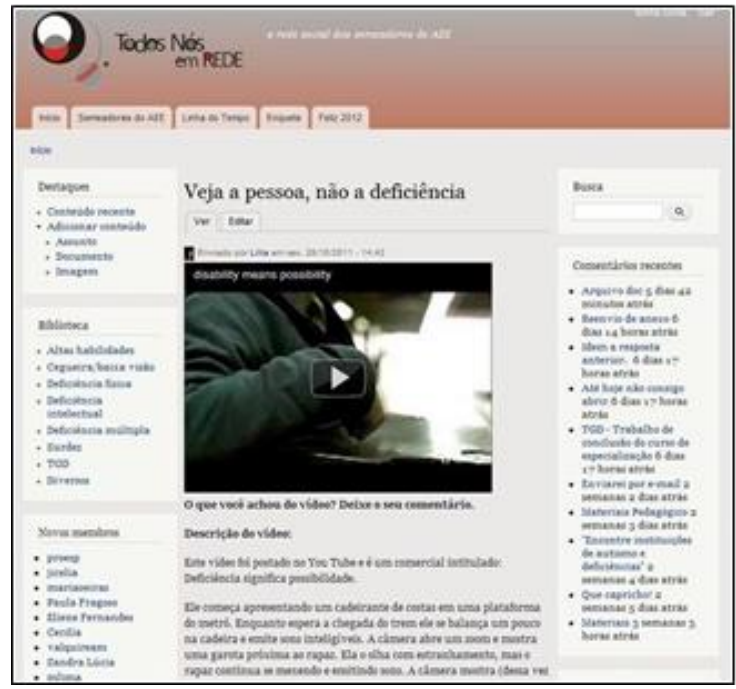

Fonte: Relatório Final PROESP/CAPES (2014)

RPGE- Revista on line de Política e Gestão Educacional, Araraquara, v. 22, n. esp. 2, p. 763-777, dez., 2018. ISSN: 1519-9029. DOI: 10.22633/rpge.unesp.v22.nesp2.dez.2018.11911 
Com as Figuras $n$. 2 e 3 demonstramos o ineditismo da proposta do TNR: a construção coletiva e participativa, que envolveu todas as seções dessa rede.

Outro diferencial que vivenciamos no TNR foi a definição participativa dos "Termos de Uso do Sistema" pelos pesquisadores e professores "semeadores" da Rede. E, ainda, a criação coletiva da "Carta de Princípios da Rede" (Figura n. 4). Esse documento mostra a preocupação com valores desses professores e com a cultura que a rede deveria disseminar (por ex: autonomia, espírito de grupo, acessibilidade).

Figura 4 - A Carta de Princípios da rede TNR

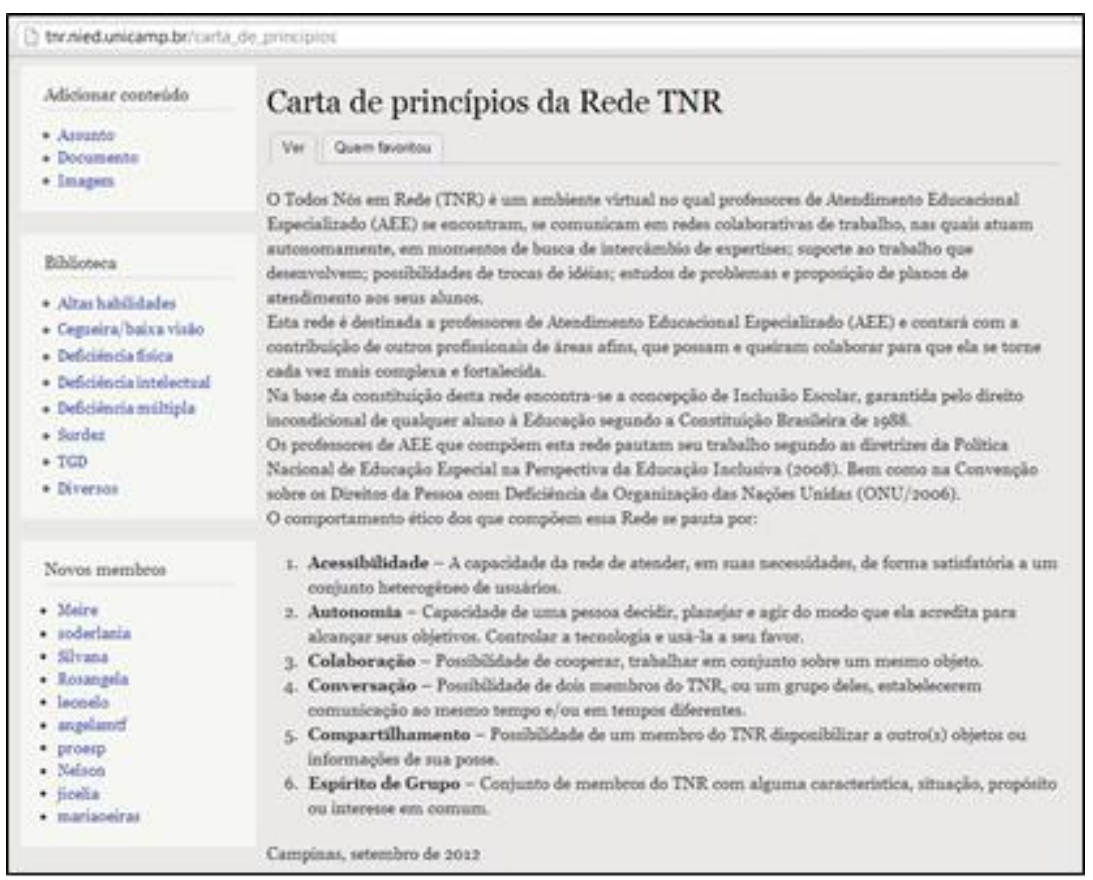

Fonte: Relatório Final PROESP/CAPES (2014)

O sistema Todos Nós em Rede continua ativo e crescendo. A rede conta atualmente com o cadastro de mais de mil professores de todo país e propicia aos participantes condições para que troquem ideias, resolvam problemas cotidianos de sala de aula de forma cooperativa e autônoma.

Para o apoio dos professores em formação autônoma o sistema TNR dispõe de seções/abas, entre elas, a seção "Nossos Casos" que possibilita que o professor compartilhe casos para serem discutidos com os demais participantes, informando dados básicos sobre o caso; o "compartilhamento de dúvidas", recurso criado para apoiar a discussão e encaminhamentos de dúvidas pontuais sobre o AEE, regulamentações, práticas, etc; o "material de apoio", destinado a troca de materiais importantes sobre o 
AEE e assuntos relacionados; "assuntos urgentes/temas importantes", a movimentação no sistema TNR é constantemente acompanhada pelos pesquisadores e professores. Assim sendo, se algum assunto urgente surge na rede um email é encaminhado para os participantes solicitando a contribuição dos demais.

Ainda objetivando fomentar a formação dos professores no sistema TNR foi criado o "Café com Bel Dias". Nesse Café, uma pesquisadora e bolsista do TNR lançava uma pergunta, gravada em vídeo e publicada no TNR, sobre a atuação dos professores em suas escola com o propósito de conhecê-los melhor, suas preocupações, necessidades etc., bem como, promover a interação entre os mesmos de um modo simples e caloroso.

A rede TNR teve e tem boa aceitação entre os professores. Entretanto, percebemos com nossas pesquisas e estudos que muitos deles ainda relutam em expor suas dúvidas diante dos colegas, alegando questões que envolvem privacidade, compartilhamento, confiança (que estão presentes na Carta de Princípios do TNR). Até o momento, constatamos que a estrutura inovadora do TNR tem contribuído para que os professores passem a agir cada vez mais de maneira autônoma e proativa.

Como rede de apoio aos professores, o TNR precisa ser mais divulgado, conhecido para que possa cada vez mais expandir os seus benefícios e assim alcançar maior número possível de professores pelo país.

\section{Encontros periódicos com redes de ensino}

O LEPED tem apoiado a formação de professores das redes de ensino, por meio de encontros semanais e mensais, via internet. Esta proposta se distingue por ser um modo simples de tratar diretamente com os professores, gestores, coordenadores e atendê-los em suas demandas locais, específicas. Temos chegado em muitas escolas de diferentes regiões, lá onde nos aguardam muitas perguntas, busca de melhores maneiras de enfrentar os desafios para que possam se manter firmes nos ideais inclusivos. Esse trabalho de apoio à inclusão foi mais um meio que encontramos no LEPED de atender aos professores de forma horizontalizada, direta e que é um sucesso. E sem custos para as partes! Trabalhamos desde o início de 2016 com diversas redes de ensino e pretendemos ampliar esse tipo de atendimento conforme a demanda.

\section{Cursos de difusão cultural}


Em 2018, conforme mencionamos anteriormente, o Leped levou a cabo outra iniciativa no sentido de oferecer apoio à efetivação das formações em educação inclusiva. Trata-se da realização dos "Cursos de Difusão Cultural" junto à Escola de Extensão (EXTECAMP) da Universidade Estadual de Campinas (UNICAMP).

Os cursos foram destinados a formar qualquer tipo de profissional, na modalidade EAD e têm características próprias, quais sejam; são rápidos, (não mais do que 4 horas); centrados em objetivos precisos, que podem ou não ser avaliados pelo cursista; utilizam tecnologias avançadas e múltiplas, que podem ser acessadas por smartphones, dentre outras; e tem baixíssimo custo para o estudante (em torno de $\mathrm{R} \$ 20,00)$; e grande capilaridade. Esses cursos têm como propósito promover a reflexão e a retomada de conceitos fundamentais em educação inclusiva, utilizando recursos inusitados e contemporâneos, tais como literatura, charges, canções, clipes, filmes, videoaulas, entrevistas e outros. Sugerimos leituras rápidas e, principalmente, questionamentos sobre a prática educacional, assim como uma bibliografia mais aprofundada sobre os temas tratados.

Os temas escolhidos para este primeiro conjunto de cursos são aqueles que os cursistas têm mais dúvidas e que têm a ver com o dia a dia escolar, tais como: como ensinar uma disciplina a todos os alunos, sem adaptações curriculares? Qual deve ser o papel do professor de AEE? O que é diferença? E o que é diversidade? Como alfabetizar alunos com surdez nas turmas comuns?

Para exemplificar o modo como trabalhamos na formação via cursos de difusão cultural, apresentamos algumas ementas, atividades e avaliações de alunos.

Figura 5 - Cursos de Difusão cultural oferecidos pelo LEPED (2o. semestre 2018)

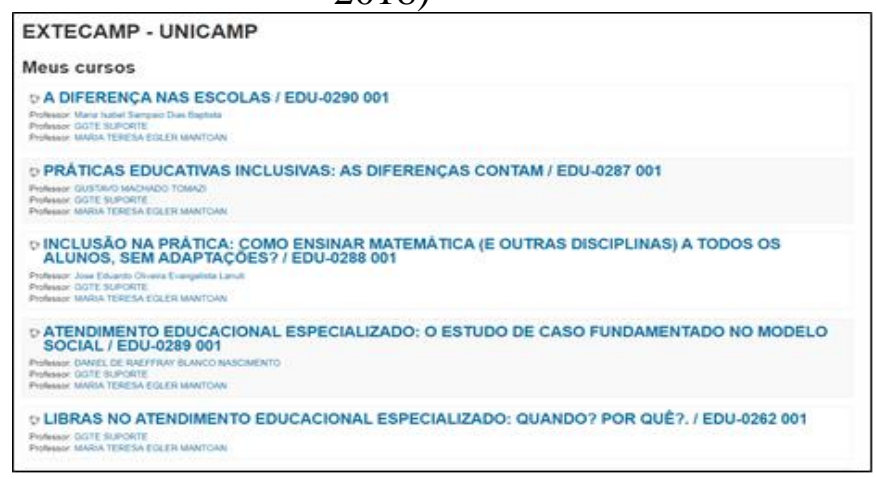

Fonte: EaD/Extemcamp/Moodle - Unicamp $(2018)^{3}$

${ }^{3}$ Disponível em: https://ead.extecamp.unicamp.br/moodle/ 
Ementa do curso "A diferença nas escolas"- Diversas formas de pensar a diferença na escola. Contraposição entre diferença e diversidade. Contextualizando a reflexão sobre a diferença através de manifestações artísticas (literatura, canções, imagens e outros). Experiência reflexiva sobre práticas escolares e diferenciações entre os alunos, sob o ponto de vista multicultural crítico. Questionamentos sobre conceitos como diferença, identidade e inclusão tendo como pano de fundo uma escola aberta a todos.

Figura 6 - Atividades sugeridas para o ítem 1 "Curso A diferença nas escolas"

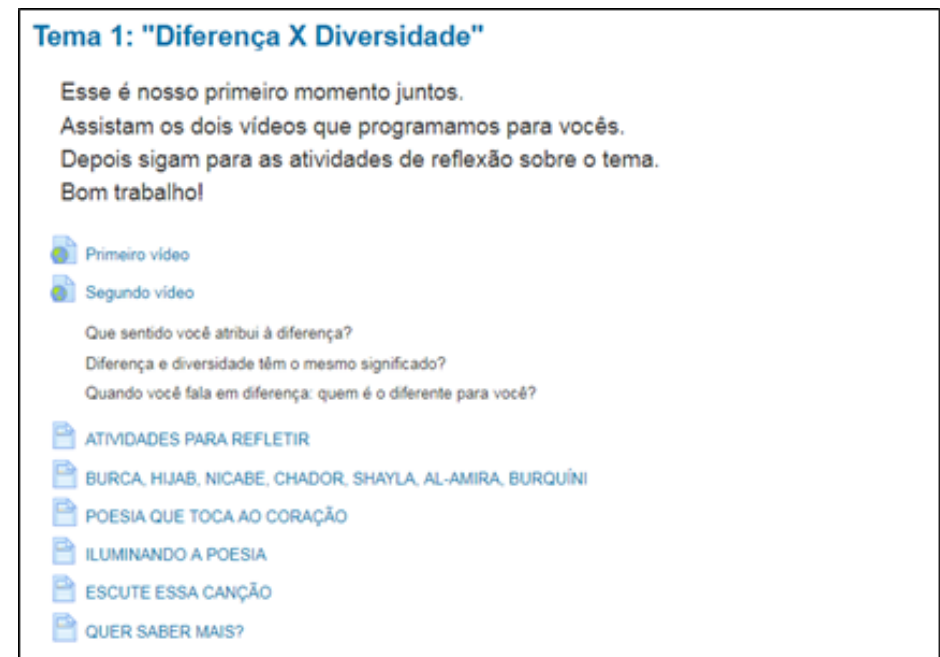

Fonte: EaD/Extemcamp/Moodle - Unicamp (2018) ${ }^{4}$

Exemplo de atividade do curso Inclusão na Prática: como ensinar matemática (e outras disciplinas) a todos os alunos, sem adaptações?

\section{VERDADEIRO OU FALSO?}

Assinale as alternativas e confira o gabarito se você acertou ou não e por quê:

1- ( ) A melhor maneira de planejar uma aula para a turma toda é oferecer atividades diferenciadas para alguns alunos que não acompanham os demais colegas. As atividades diferenciadas possibilitam a participação e o aprendizado de todos os alunos em uma mesma sala de aula.

2- ( ) Os alunos com deficiência, em uma escola para todos, precisam de atividades diferenciadas para melhor aprender.

\footnotetext{
${ }^{4}$ Disponível em: https://ead.extecamp.unicamp.br/moodle/
} 
3 - ( ) Planejar uma aula é uma prática colaborativa que envolve, de um lado, o conteúdo curricular a ser ensinado pelo professor e, de outro, o envolvimento (curiosidades, indagações e conhecimentos anteriores dos alunos de sua turma).

Exemplo de atividade do curso: Práticas Educativas inclusivas: As diferenças contam

Figura 7 - Animação feita por alunos do sexto ano do PRODECAD/UNICAMP para estudo do tema: "Acesso de todos os alunos à escola"

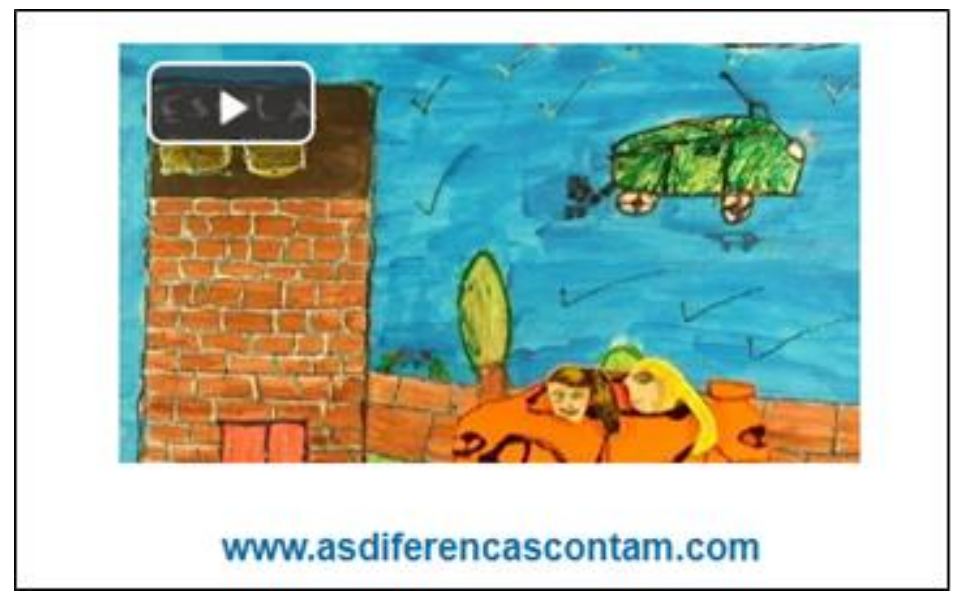

Fonte: asdiferencascontam.com (2018)

Para encerrar reproduzimos excertos de duas avaliações que nos foram enviadas por alunos dos cursos "A diferença nas Escolas" e "Inclusão na Prática":

Gostaria de deixar algumas colocações sobre o conteúdo, a forma de abordagem do tema e outras impressões:

1. A utilização dos recursos como vídeos, as canções, os testes de conhecimentos, textos literários, indicações de leitura para aprofundamento estimulam a reflexão, foram muito bem empregados, assim como a sequência utilizada.

2. Sobre o conteúdo, as letras das canções, a escolha dos assuntos trazidos nos vídeos, o "Poesia que toca ao coração", e outros itens conseguiram promover um novo olhar sobre o conceito de o que é ser diferente; não apenas nas escolas, mas em todos os contextos e meios organizacionais. 3. E como disse Lenine na composição "Ninguém faz ideia de quem vem lá”. Todos são diferentes...ninguém faz ideia...A aceitação, e assim como toda abordagem trazida nesse curso deixa uma reflexão para os educadores. (Curso "A diferença nas escolas") 
Olá professor, achei muito bom, de fácil entendimento e nada entediante. Fiquei muito surpresa, pois tinha uma visão muito equivocada sobre inclusão na sala de aula. O conteúdo me deu outra visão e apesar da importância extrema é de fácil compreensão. (Curso "Inclusão na Prática").

Devido ao grande sucesso que obtivemos com esses Cursos de Difusão Cultural planejamos outros e re-ofereceremos os que já aconteceram neste segundo semestre de 2018.

\section{Publicação trimestral do LEPED: “Cá entre nós”}

Figura 8 - Primeira edição em papel do “Cá entre Nós” (março de 2018)

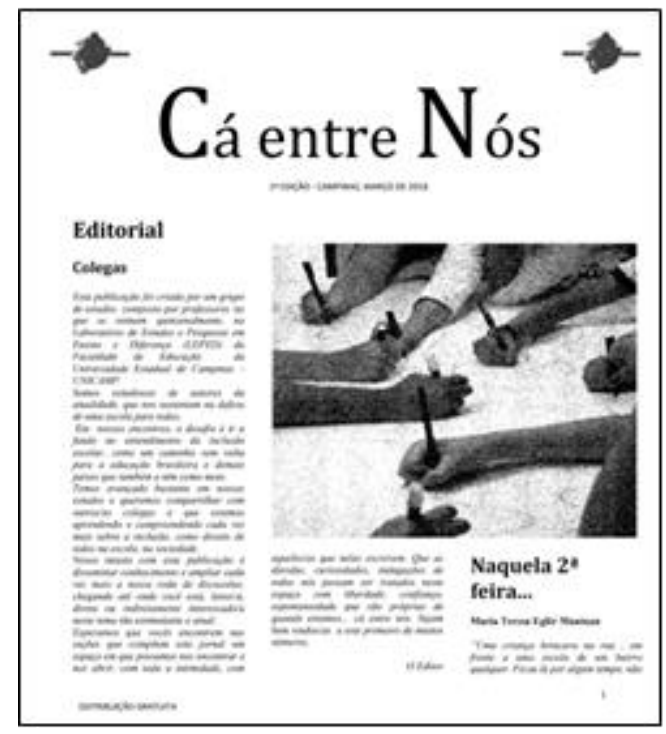

Fonte: Cá entre nós (2018)

A ideia dessa publicação trimestral do LEPED, em papel e em formato digital, é contribuir para disseminar conhecimento e ampliar cada vez mais a roda de discussões que realizamos quinzenalmente no LEPED. Nesses encontros estudamos autores da atualidade que sustentam a defesa de uma escola sem discriminações e preconceitos. $\mathrm{O}$ "Cá entre nós" apresenta pequenos textos, ensaios, entrevistas com educadores, em uma linguagem acessível. O site desta publicação propicia trocas entre autores de cada edição e os leitores, prolongando e extensão dos temas tratados no jornal.

Esta é mais uma iniciativa do LEPED de estimular os professores a se encontrarem e estudarem. O tablóide é distribuído gratuitamente e sua tiragem atual é de 2000 exemplares por edição. 


\title{
Finalizando
}

\begin{abstract}
Acontece que o mundo é sempre grávido de imenso. E os homens, moradores de infinitos, não têm olhos a medir. Seus sonhos vão à frente de seus passos. Os homens nasceram para desobedecer aos mapas e desinventar bússolas. Sua vocação é a de desordenar paisagens. (COUTO, 1991, p. 167)
\end{abstract}

A vanguarda de nossos estudos e interesses pela democratização do ensino sempre embalou sonhos, intenções e propostas do LEPED e de seus membros. O espírito empreendedor e audacioso que buscamos imprimir em nossos trabalhos na área da educação levou-nos a pesquisar novos caminhos pelos quais pudéssemos explicitar aos professores o sentido de uma nova escola e práticas pedagógicas para concretizá-la.

O mundo é sempre grávido de imenso e nós, do Leped, não conseguimos ter olhos a medir: nascemos para desobedecer aos mapas e reinventar bússolas. Acreditamos que essa seja a força motriz que nos impulsiona a propor estudos e pesquisas que refletem nossa alma, pois, precisamos fundamentar nossa prática e estamos completamente comprometidos com a inclusão escolar.

Para nós o trabalho que realizamos representa puro oxigênio, portanto, nos é natural o envolvimento em iniciativas como as aqui narradas, que visam à contínua formação de professores segundo a perspectiva da educação inclusiva.

\section{REFERÊNCIAS}

BAPTISTA, M. I. S. D. Danças no TNR: movimentos de professores em formação continuada. 236f. Tese Doutorado (Doutorado em Educação) - Faculdade de Educação, Universidade Estadual de Campinas, Campinas, 2018.

\section{BARANAUSKAS, M. C. B.; MANTOAN, M. T. E. Redes Sociais e Autonomia} Profissional: novos rumos para formação continuada a distância de professores de AEE. PROESP/CAPES, 2009.

BRASIL, Ministério da Educação. Secretaria de Educação Especial. Política Nacional de Educação Especial na Perspectiva da Educação Inclusiva. Brasília: MEC/SEESP, 2008.

CAVALCANTE, B. M. A importância de uma rede social para o aperfeiçoamento continuado dos profissionais do atendimento educacional especializado. $179 \mathrm{f}$. Dissertação (Mestradoem Educação), Faculdade de Educação da Universidade Estadual de Campinas, 2010.

COUTO, M. Cronicando. 7 ed. Editorial Lisboa, 1991. 
MANTOAN, M.T.E. (Org.). As escolas e suas transformações, a partir da educação especial, na perspectiva da educação inclusiva. Campinas, SP: Librum, 2014.

\section{MANTOAN, M. T. E.; BARANAUSKAS, M. C. B. Relatório final PROESP/CAPES,} 2014. Disponível em:

http://erytheia.nied.unicamp.br:8081/interhad/publicacoes/reports/relatorio-finalprojeto-proespcapes.pdf. Acesso em: 20 set. 2018.

NASCIMENTO, D. R. B. O discurso de todos nós: um estudo sobre a rede social de formação continuada de professores todos nós em rede. 196f. Dissertação (Mestrado em Educação), Faculdade de Educação da Universidade Estadual de Campinas, Campinas, 2017.

PEREIRA, R. Rede de Autoridades e Apoio às Interações Sociais na Web: uma Abordagem Culturalmente Informada. Tese (Doutorado em Computação), Instituto de Computação Universidade Estadual de Campinas, Campinas, 2012.

ROCHA, H.; BARANAUSKAS, C. Design e avaliação de interfaces humanocomputador. Campinas, SP: NIED/UNICAMP, 2003.

\section{Como referenciar este artigo}

MANTOAN, Maria Teresa Eglér.; BAPTISTA, Maria Isabel Sampaio Dias. Inovar para fazer acontecer: como estamos fortalecendo redes de apoio à educação inclusiva. Revista on line de Política e Gestão Educacional, Araraquara, v. 22, n. esp. 2, p. 763 777, dez., 2018. ISSN: 1519-9029. 10.22633/rpge.unesp.v22.nesp2.dez.2018.11911

Submetido em: 05/11/2018

Aprovado em: 20/11/2018 